\title{
A Conceptual Model of the Role of Communication in Surrogate Decision Making for Hospitalized Adults
}

\author{
Alexia M. Torke, MD, MS ${ }^{1,2,3}$, Sandra Petronio, PhD $^{2,4,5,6}$, Greg A. Sachs, MD ${ }^{1,3}$, Paul R. \\ Helft, MD $^{2,7}$, and Christianna Purnell ${ }^{1}$ \\ ${ }^{1}$ Indiana University Center for Aging Research, Regenstrief Institute, Indianapolis, IN \\ ${ }^{2}$ Fairbanks Center for Medical Ethics, IU Health, Indianapolis, IN \\ ${ }^{3}$ Division of General Internal Medicine and Geriatrics, Indiana University School of Medicine, \\ Indianapolis, IN \\ ${ }^{4}$ IUPUI Department of Communication Studies, Indianapolis, IN \\ ${ }^{5}$ Indiana University School of Nursing, Indianapolis, IN \\ ${ }^{6}$ Indiana University School of Informatics, Indianapolis, IN \\ ${ }^{7}$ Indiana University Melvin and Bren Simon Cancer Center, Indianapolis, IN
}

\begin{abstract}
Objective-To build a conceptual model of the role of communication in decision making, based on literature from medicine, communication studies and medical ethics.

Methods-We propose a model and describe each construct in detail. We review what is known about interpersonal and patient-physician communication, describe literature about surrogateclinician communication, and discuss implications for our developing model.

Results-The communication literature proposes two major elements of interpersonal communication: information processing and relationship building. These elements are composed of constructs such as information disclosure and emotional support that are likely to be relevant to decision making. We propose these elements of communication impact decision making, which in turn affects outcomes for both patients and surrogates. Decision making quality may also mediate the relationship between communication and outcomes.
\end{abstract}

Conclusion-Although many elements of the model have been studied in relation to patientclinician communication, there is limited data about surrogate decision making. There is evidence of high surrogate distress associated with decision making that may be alleviated by communication-focused interventions. More research is needed to test the relationships proposed in the model.

Practice Implications-Good communication with surrogates may improve both the quality of medical decisions and outcomes for the patient and surrogate.

(c) 2011 Elsevier Ireland Ltd. All rights reserved.

Corresponding Author: Alexia M. Torke, MD, MS, IU Center for Aging Research, HITS Building Suite 2000, 410 W. $10^{\text {th }}$ St., Indianapolis, Indiana 46208, atorke@ iupui.edu.

Publisher's Disclaimer: This is a PDF file of an unedited manuscript that has been accepted for publication. As a service to our customers we are providing this early version of the manuscript. The manuscript will undergo copyediting, typesetting, and review of the resulting proof before it is published in its final citable form. Please note that during the production process errors may be discovered which could affect the content, and all legal disclaimers that apply to the journal pertain. 


\section{Keywords}

proxy; decision making; communication

\section{Introduction}

When hospitalized patients develop cognitive impairment, physicians often must work with family members or other surrogates to make complex medical decisions for the patient. It is essential to recognize that the family member is often making decisions in the context of high stress, grief, and an unfamiliar hospital environment. ${ }^{1-3}$ In such a context, high quality communication is essential to good decision making. However, there is growing evidence that communication quality may often be poor. In the hospital setting, up to one third of family members of seriously ill patients report problems with physician communication and decision making, ${ }^{4}$ and over a third have concerns about family support. ${ }^{5}$ Both family members and medical staff of Intensive Care Unit (ICU) patients report high levels of conflict. $^{6-7}$ There is evidence that communication with surrogates is often delayed ${ }^{8}$ even though early communication has been shown to reduce surrogate distress. ${ }^{9}$

Traditional frameworks for surrogate decision making have focused on the ethical principles and guidelines that are central to decision making. ${ }^{10-11}$ Although such guidelines are essential, less attention has been paid to the communication or relational aspects of the decision making process. We propose that we will be better able to improve the process of decision making between surrogates and clinicians if we begin with a strong conceptual understanding of the role of communication in the decision making process. This undertaking is well suited to an interdisciplinary approach, combining findings from the fields of medicine, communication studies, and medical ethics. The goal of this manuscript is to build a conceptual model of the role of communication in surrogate decision making that will serve as a guide for researchers in the development of observational studies and future interventions. Theoretically, this model can be applied to other types of surrogate decision making issues. However, the hospital setting provides a good testing ground because decisions are often of a life and death nature and often must be made urgently. These factors heighten the need for effective communication and accentuate lapses in communication that lead to poor decision making.

\section{Overview of the Model}

Communication theorists have proposed two fundamental aspects of interpersonal communication: a content dimension, and a relationship dimension (see Figure). ${ }^{12-13}$ The content dimension includes information that is conveyed between the participants. In our model, we named this function "information processing" to reflect both the content of information and the manner in which this information is understood by the recipient. The relationship dimension of the model, called "relationship building," includes trust, emotional support, and consensus/conflict between the participants. Our model proposes these two dimensions influence the quality of medical decisions made by surrogates and clinicians. Based on work in the decision making ${ }^{14-15}$ and oncology literature ${ }^{16}$ the model defines high quality medical decisions as those that are informed, concordant with the patient's values, and mutually endorsed by patients, surrogate, and providers. The model therefore proposes that the quality of medical decisions impacts outcomes for both patients and surrogates.

The majority of examples in this manuscript will focus on the case of a single surrogate. Although some elements of the model can also be applied to cases where multiple family members participate in decision making, a detailed discussion of the interfamily dynamics is 
beyond the scope of this paper. Also, the model assumes that the patient is completely unable to participate in decision making. We acknowledge that in some cases, patients may be partially or intermittently able to participate in the process. While additional constructs not included in the model may potentially play a role in surrogate decision making, we have selected those that are critical to communicative functioning based on existing research literature.

Below we explain each element of the model in detail. We have used the model (see Figure) as a means to structure the literature review. Each element corresponds to a heading or subheading in the manuscript. We first describe what is known about each construct in the model from literature addressing interpersonal communication or patient-physician communication. We then describe any available literature about surrogate-clinician communication. Finally, we discuss the implications of the literature for our developing model.

\section{Information Processing}

To make medical decisions, both surrogates and clinicians must convey and process information about the patient's history, current condition, and prognosis. Although the clinician is likely to provide the medical information, the surrogate often brings expertise about the patient's preferences and values. ${ }^{10}$ The participants make sense of this information in light of their prior knowledge and expectations. ${ }^{17}$

\subsection{Information Disclosure}

Disclosure by clinicians is the first step needed for information processing. Prior research has addressed patients' own preferences for disclosure of medical information. Studies have found that most, but not all patients, desire to be informed about their own medical conditions and decisions. ${ }^{18-19}$ In addition to using information for decision making, patients may have additional reasons for desiring it, such as wanting to know what to expect in the future. ${ }^{20}$ However, patients can be overwhelmed by the volume of information they learn about their disease ${ }^{16,21-22}$

Patients' perceptions about the disclosure of medical information can be understood using the theory of Communication Privacy Management (CPM). This theory proposes that individuals feel a sense of ownership over information about themselves, and believe that they should have authority over when and how that information is disclosed to others. ${ }^{23}$ Patients believe that physicians have a responsibility to disclose information to them because physicians are privy to sensitive information about the patient that the patient may not otherwise have access to. ${ }^{24}$

It is likely that surrogates, similar to patients, feel a sense of ownership and entitlement regarding the disclosure of patient information. In addition, they must navigate being responsible for someone else's information and choices. For example, the surrogate may perceive that the physician has an obligation to disclose medical information about the patient to them. Clinicians may not be aware that surrogates feel this sense of ownership regarding the information. They may be caught off guard to learn that surrogates expect to be fully informed.

Surrogates, similar to patients, are likely to have a conflicting sense of both desiring information and wanting to avoid that information. They may find certain information stressful or challenging to hear. Physicians may not take into account that disclosing information about a poor prognosis or limited life expectancy to a surrogate could have the same devastating impact it has if it were disclosed to the patient. Thus, it is clear that similar 
to interacting with patients, assessing the surrogate's need for and ability to cope with information is a key part of the communication process that has the potential to improve decision making.

CPM theory can also illuminate information management when several surrogates are involved. Families also have complex rules about how information is shared within the family structure. ${ }^{25}$ Physicians may make different assumptions than the surrogate regarding when and how to disclose information to various family members about the patient's current illness. ${ }^{24}$ For example, the surrogate may want to withhold information from some family members. Alternatively, several family members may feel entitled to discuss all the information with the physician and to participate in decision making. Clinicians may prefer speaking to the legally authorized surrogate or asking that the family appoint one person to receive information. The clinician may perceive that such a move will clarify decision making authority or decrease the amount of time required for communication. Clinicians who are aware of surrogate's expectations for information disclosure will be better prepared to manage them.

Disclosure of information to families may be complicated by clinicians' concerns about violating patient privacy. The passage of the Health Insurance Portability and Accountability Act (HIPAA) in 1996 lead to an increased focus on many aspects of patient privacy, but also some degree of misunderstanding of the limits on sharing information with families. ${ }^{26}$ HIPPA does not prevent clinicians from keeping surrogates informed in cases where the patient is incapacitated. It is ethically and legally justifiable to share any information needed for the surrogate to make good decisions and participate in the patient's care. ${ }^{26}$

\subsection{Sense Making}

For many patients and their surrogates, the hospital is a complex and unfamiliar environment. In any such new environment, newcomers must quickly make sense of the surroundings and learn to effectively function within them. ${ }^{27}$ In such cases, individuals rely heavily on both communication with others and on cues from the environment to develop an understanding of the organization and the events occurring within it. ${ }^{28}$

If the surrogate is unfamiliar with that particular hospital or had not tried to navigate a hospital environment before, the surrogate will need to quickly learn how to function in the hospital. Even if the surrogate had been a patient in that hospital or at some other hospital, functioning as a surrogate is likely to be a different and not necessarily familiar experience. The responsibilities of the surrogate role and the urgency of the patient's needs may place new cognitive and emotional burdens on the surrogate.

In addition to navigating the environment, surrogates must use the medical information provided to develop an understanding of the patient's condition. This may be difficult if they are emotionally or cognitively unprepared for what they learn about the patient's condition. Some methods of delivering news can help prepare the patient to process new and difficult information. For example, Buckman's model of delivering bad news ${ }^{29}$ involves delivering a warning statement to psychologically prepare the patient for what they are about to hear. This process of sense making is essential to acquiring information and using it to make difficult decisions.

\subsection{Expectations}

Patients enter a clinical encounter with expectations about the clinicians' behavior and about the outcomes of the encounter. ${ }^{17}$ Work on physician-patient communication has found that exploring patient concerns early in a clinical encounter can facilitate diagnosis and treatment because it allows for an early understanding of the patient's expectations for the visit and 
explanatory model. ${ }^{30}$ These and other communication strategies have been incorporated into a research tool that allow for coding physician-patient encounters to document the manner in which physicians explore and respond to patient concerns. ${ }^{31}$

Surrogates are also likely to enter the hospital with expectations about the experience, including the care the patient will receive and their own role in that care. Such expectations are likely to be based on the surrogate's prior experiences in seeking healthcare for him or herself or for the patient. They may also be developed from the media, professional experiences or general levels of trust in institutions. The surrogates' own explanatory model of disease is likely to affect how they interpret information and their experiences during the hospitalization. ${ }^{17}$ Furthermore, these expectations may be modified by incidents occurring early in the hospital stay.

Expectations regarding the patient's care and outcomes are likely shaped in large part by communication with clinicians. When communication is poor, it is possible that the clinician and surrogate have divergent understandings about the patient's condition, different expectations regarding the patient's medical care, and possible outcomes. Both the content and the timing of communication are likely to impact the extent of mutual understanding and agreement. Torke et al found that early and frequent communication with surrogates is associated with physician assessments of communication effectiveness. ${ }^{32}$ Other studies have shown that mandatory family meetings occurring soon after admission to the ICU decreased patient days in the ICU ${ }^{33,9}$ and surrogate distress. ${ }^{9}$ Early communication may lessen surrogate distress by creating shared expectations about the hospital experience and about patient prognosis. Further research is needed to better understand the optimal timing of communication with surrogates.

\section{Relationship Building}

In order to make health care decisions for a patient, surrogates must establish a working relationship with physicians and other health care providers. The growing model of hospitalist physicians who do exclusively inpatient care means that an increasing number of patients and families have never met their physician before hospital admission. ${ }^{34}$ Although the patient has at least some opportunity to build a new relationship through daily rounds with the patient, families may not be present at the bedside during rounds. Therefore, they have even less of a chance to build a relationship with the physicians. ${ }^{3}$

The literature on medical decision making and relationship-centered care has identified many elements critical to good relationships with patients, ${ }^{35}$ but there is little information on the process of relationship building between surrogates and clinicians. Building these surrogate-clinician relationships presents special challenges in the hospital setting in the context of an acute illness. ${ }^{1-3}$ Based on our review of the literature, we have identified four potential constructs that are important in the development of relationships between health care providers and surrogates: emotional support of the surrogate, trust, consensus and conflict, and surrogate roles and participation.

\subsection{Emotional Support}

A growing literature addresses the emotional experiences of the surrogate. There is evidence that making surrogate decisions in the hospital can be extremely stressful for both surrogates and physicians. One study found higher post traumatic stress symptoms in ICU family members who participated in decision making than those who did not. ${ }^{36}$ Qualitative studies have examined the experience of the surrogate in other settings such as the nursing home ${ }^{37-38}$ or ICU, ${ }^{39-40}$ or have interviewed the family members of veterans, ${ }^{41-43}$ of patients who died after withdrawal of life-sustaining treatments, ${ }^{44-45}$ and family members 
who have made a decision about a feeding tube ${ }^{46-47}$ Both these and quantitative, survey based studies ${ }^{48}$ have consistently shown that the decision making process was stressful to family members. There is also evidence that the process is difficult for physicians, with over $20 \%$ stating that making such decisions caused them distress. ${ }^{32}$ In physician interviews, ${ }^{49}$ physicians identified communication problems that stemmed from differing expectations, hospital and physicians' schedules, and difficulty contacting surrogates as barriers to communication.

Research with surrogate decision makers in the ICU has identified important emotional tasks of the surrogate, including coming to terms with the patient's illness, ${ }^{45}$ accepting the responsibility of decision making, ${ }^{45}$ and maintaining family roles and relationships. ${ }^{44}$ These tasks must be accomplished in the context of high stress from the patient's illness, anxiety about the outcome, and disruptions to their daily routines and relationships due to the illness.

In the ICU setting, observational studies have identified characteristics of communication that are associated with patient satisfaction and that relate directly to emotional support, including increased time for the family to speak in family conferences, ${ }^{50}$ increased expressions of empathy ${ }^{51}$ and consistent communication by heath care team members. ${ }^{52}$ Based on this work, authors have developed a framework entitled VALUE (value, acknowledge, listen, understand, elicit) to help clinicians provide support in communication with families. In contrast, behaviors that reject or ignore the surrogate's point of view may be destructive to the relationship. ${ }^{12}$ Finally, providing information about the disease has been shown to help patients achieve a greater sense of control and hope. ${ }^{53}$ Research is needed to further explore whether the provision of information is also perceived to be supportive by surrogate decision makers.

\subsection{Trust}

Our model proposes trust is an element of relationship building that likely impacts decision making and thus outcomes for patients and surrogates. Researchers have proposed that health care transactions are more effective if trust is high. ${ }^{54}$ Less frequent or more difficult interactions with clinicians may adversely affect the quality of medical decisions. Although there is evidence that distrust in the health care system is associated with poorer self-rated health, ${ }^{54}$ we know little about the mechanism of this relationship or whether steps to improve trust on the part of patients or their surrogates could affect health outcomes.

Trust has been studied in relation to a particular physician, to insurers and to health care systems generally. In a relationship with a clinician, trust can be defined as a belief that the clinician "will be present, committed to the patient's best interest and technically competent." 16 Trust in the physician is positively correlated with satisfaction and self-rated health, ${ }^{55}$ treatment adherence ${ }^{56}$ and healthy behaviors. ${ }^{57}$

Rose et al ${ }^{58}$ identified 4 dimensions of trust in the health system, including honesty, confidentiality, competence and fidelity. These authors found that trust in the health system is generally much lower than trust in one's personal physicians. ${ }^{54}$ Studies have found that a person's trust in the health care system is associated with self-reported health status. ${ }^{54}$ It remains to be determined whether a surrogate decision maker's trust in clinicians or the health care system affects outcomes for patients unable to make their own medical decisions.

Surrogates enter the hospital with a particular level of trust in both clinicians and the health care system. Our model proposes that trust impacts communication and also impacts outcomes for patients and surrogates. Future research is needed to test these relationships. However, it is possible that trust is also modified through communication experiences that 
occur during the hospitalization itself. Trust may be promoted when there is high quality communication. In contrast, trust may be threatened by poor quality communication or by experiences that do not meet the surrogate's expectations for health care. One example of a potentially unexpected experience is that clinicians may recommend withholding or withdrawing medical treatments from a seriously ill hospitalized adult. Such limitations may be met with diverse reactions from surrogates. They may be welcomed by the surrogate or perceived as a relief. They also may be interpreted as abandoning or "killing" the patient, or as arising from a desire by the clinician or health system to save money. Such experiences may undermine a sense of trust and may have long-term consequences for future communication and for the patient's care.

\subsection{Consensus and Conflict}

Professional guidelines have advocated consensus as an ideal for decision making with surrogates. ${ }^{59}$ However, there is some evidence suggesting high levels of conflict between medical staff and families in the ICU setting. ${ }^{6-7}$ One study of surrogate decision making in the ICU found that conflict, although rare, could be prolonged in some cases. ${ }^{60}$ Others have found that conflict is a cause of moral distress for both nurses and physicians. ${ }^{61-62}$

In a survey of physicians, we found evidence that disagreement and conflict are distinct concepts that have different implications for decision making. ${ }^{32}$ Likely it is possible to disagree yet still reach consensus. Although we have included consensus and conflict as elements of relationship building, they also could be considered outcomes of decision making. These in turn could affect other patient and surrogate outcomes and could also feed back to impact future decisions.

\subsection{Roles and Participation}

When a surrogate and a clinician communicate, they must negotiate each party's role in the relationship. There is evidence that patients have preferences for their own role and the role of the clinician. ${ }^{16,63}$ Overall, patients seem to favor shared or patient-centered decision making, but there are others who prefer that physicians make most or all decisions. ${ }^{18-19,}$, $64-65$ Congruence between the physician's style and the patient's preferences may be an important element of trust. ${ }^{66}$

Because research on surrogate decision making has focused primarily on whether the decision making process upholds the patient's autonomy through mechanisms such as advance directives and substituted judgment, we know less about how the clinician and surrogate navigate decision making roles and participation at the time that the decision must be made. Navigating these roles and level of participation may be even more complex in communication with surrogates because the moral authority of surrogates may not be as widely agreed upon as the authority of patients to make their own decisions. ${ }^{2}$ As we discuss below, standard legal and ethical approaches to surrogate decision making have been widely criticized in recent years, leading to uncertainty about how such decisions should be approached.

Shared decision making is a model that may best address the need for negotiation of roles in clinician-surrogate communication. Shared decision making is characterized by a two-way exchange of both information and decision making between the clinician and patient. It includes mutual participation of the patient and clinician, adequate sharing of information in order to achieve informed consent and a final decision that is mutually endorsed ${ }^{67}$ In the past decade, there has been considerable enthusiasm for such shared decision making, ${ }^{68}$ in part motivated by research linking it to higher patient satisfaction ${ }^{69}$ and improved clinical outcomes in chronic disease. ${ }^{70-71}$ Others have argued that it is an important component of 
good communication with patients and families at the end of life. ${ }^{72}$ When surrogates and clinicians begin a dialogue about a serious medical decision, it may be valuable to explicitly discuss the role the surrogate expects and desires to play in communication and decision making.

\section{High Quality Medical Decisions}

A recent extensive exploration of communication in oncology identified high quality medical decisions as an important intermediate outcome of health care that is impacted by communication quality and that also impacts health outcomes for patients. ${ }^{16}$ Building on the shared decision making model, the authors identify three elements of high quality decisions. They are: 1 . informed by clinical evidence; 2 . concordant with values, and 3. mutually endorsed. An informed choice requires that the surrogate have an understanding of the patient's medical status, the potential risks and benefits of the proposed intervention and alternatives, and a professional opinion from the physician. ${ }^{73}$ As we have discussed, the amount of information the surrogate desires or is able to understand may vary from case to case. Clinicians must take steps to ensure that the surrogate is provided with information in a manner he or she can understand and can use to make decisions.

The ideal decision is concordant with both clinicians' and surrogates' values, as well as the patient's values to the extent that they are known. Ethical frameworks for surrogate decision making have focused on the extent to which the decision upholds three main standards of decision making: 1 . Advance directives, in which the patient has previously expressed wishes for care; 2 . Substituted judgment, in which the surrogate attempts to determine what the patient would have decided if able; and 3. Best interests, in which the burdens and benefits of treatment are considered. ${ }^{10}$ A high quality decision would meet at least one of these standards. Such frameworks have been criticized on the grounds that surrogates are generally poor predictors of patients wishes for treatment. ${ }^{74}$ It may be impossible to determine what the patient would have wanted in a given scenario even with the help of an advance directive. ${ }^{75}$ Surrogates may in fact rely more on the types of treatments they would choose for themselves rather than on what the patient would have wanted. ${ }^{76}$ Others have pointed out that although substituted judgment is unlikely to reflect the actual wishes of the patient, asking what the patient would have wanted may reflect other key values, such as respecting the patient as a person ${ }^{77}$ or making a decision that is an authentic reflection of the patient. ${ }^{78}$ These complex ethical issues may be a reason why issues related to surrogate decision making make up a high percentage of ethics consults. ${ }^{79}$

Mutual endorsement is the third criterion of a high quality medical decision. Mutual endorsement can help both the surrogate and the clinical team in carrying out the decision. Further research is needed to explore whether endorsement of the decision is related to the surrogate's satisfaction with care as well as the surrogate's own later distress. Ideally, the treatment decision is the one that the surrogate and clinician think is best. However, it is possible that the parties fundamentally disagree about the best course of action but are able to negotiate a decision that both are willing to endorse. The decision may be best characterized as one of mutual acceptance ${ }^{67}$ or accommodation. ${ }^{80}$

Prior research has examined whether patients are receiving care that is consistent with their own preferences or the preferences of their surrogate. ${ }^{81-83}$ In most cases of surrogate decision making, it is no longer possible to determine what the patient would have wanted. Given the strong legal and ethical reliance on surrogate decision making in current medical ethics, it is still important to assess whether the surrogate's preferences for care are being honored. Future research should examine whether high quality surrogate-clinician 
communication improves the match between the care the surrogate endorses and the care that is received by the patient.

\section{Patient and Surrogate Outcomes}

Our model proposes that clinician-surrogate communication affects medical decision making, which in turn affects outcomes for the patient and surrogate. Decision making can be thought of as an intermediate outcome, but also a factor that may mediate the relationship between communication and outcomes. ${ }^{16}$ Epstein has noted that research on the relationships between communication and patient outcomes is at its early stages ${ }^{16}$ and this is even more so for the case of surrogate decision making. Identifying appropriate outcomes in studies of seriously ill patients who cannot express treatment preferences is complex for several reasons. In many cases the goals of care are palliative rather than curative. ${ }^{125}$ Traditional outcomes such as decreased mortality or improving health may not be achievable. Other goals may be more appropriate, such as increasing the use of palliative care, reducing care that is non-beneficial, or improving the satisfaction and well-being of family members. Many studies of surrogate decision making have examined whether surrogate decisions match the hypothetical decisions that the patient would have made. ${ }^{74}$ In clinical practice, however, it is rare that the patient regains capacity and can determine whether the decision is one he or she would have made. For this reason, it is necessary to use other standards to assess the outcomes of decision making.

Interventions for dying patients in the ICU have shown that early family meetings increase the rate of withdrawal of mechanical ventilation from 14 to $27 \%,{ }^{9}$ and intensive communication $^{33,84}$ and ethics consultation ${ }^{85}$ reduce length of ICU stays. A recent randomized controlled trial found that palliative care for patients with lung cancer reduced the use of life-sustaining care just before death. ${ }^{86}$ Although increased survival may not always be possible at the end of life, this study found that patients who received palliative care actually lived longer than those who received usual care.

Studies on palliative care have aimed to reduce unnecessary or non-beneficial care while continuing care that is beneficial to the patient. For example, some studies have examined the use of aggressive, life-sustaining care that is unlikely to impact outcomes based on worsening scores on a disease severity measure, the Acute Physiology and Chronic Health Outcome Evaluation (APACHE) ${ }^{87-88} \mathrm{~A}$ fear of those skeptical of palliative and hospice care is it may in fact hasten death. To counter this concern, some palliative care researchers have examined mortality rates between treatment and control groups to demonstrate that they are similar. In other words, palliative care should improve the quality of care and decrease non-beneficial care while not increasing mortality. ${ }^{85}$

Surrogate satisfaction is another important outcome of decision making. In the absence of direct feedback from the patient, the surrogate provides the best assessment of the quality of care and communication. There a body of evidence linking physician-patient communication to patient satisfaction. ${ }^{69}$ Interventions have found that family satisfaction can be increased interventions such as routine ethics consultation. ${ }^{85}$ In the nursing home setting, taking more time to discuss advance directives upon admission to the nursing home is associated with greater family satisfaction. ${ }^{89}$ Additional work is needed in the inpatient hospital setting to determine the elements of quality communication that are related to surrogate satisfaction.

Finally, surrogate distress is an important consequence of surrogate decision making. Prior research has found negative outcomes, such as anxiety, guilt and stress, for surrogates who made major decisions in a variety of clinical settings. ${ }^{48}$ In fact, surrogates in the ICU report high levels of post traumatic stress symptoms. ${ }^{36}$ Lautrette et al found that early family meetings actually decreased the proportion of family members who had post traumatic stress 
symptoms from 69 to $45 \% .^{9}$ This study also found reductions in anxiety and depression. These findings highlight the substantial stress caused by both hospitalization and decision making for a family member. In fact, merely having a family member hospitalized is associated with increased mortality for a spouse. ${ }^{90}$ There is an important public health case for addressing the outcomes of family members of hospitalized adults in order to reduce the negative outcomes of distress, anxiety, depression and even death.

\section{Discussion and Conclusions}

As the population ages and the incidence of conditions such as dementia rise, surrogate decision making will become even more necessary in the hospital setting. In order to improve the outcomes of care for patients and their surrogates, it will be necessary to gain a better understanding of the relationship between surrogate-clinician communication and outcomes. Our model proposes that two fundamental aspects of communication, information processing and relationship building, contribute to the quality of medical decision making. We have identified an operational definition of decision making quality created for cancer patients but that is appropriate for all types of medical decisions. We then propose that the quality of medical decisions directly impacts outcomes for both the patient and the surrogate. In this framework, decision making quality can be considered an intermediate outcome between communication and patient/surrogate outcomes. Decision making quality may also mediate the relationship between communication and outcomes. We have designed the model to apply to a broad range of surrogates for adult patients, including close family members and other appointed health care representatives. A similar model may also apply in other decision making situations, such as surrogate decision making in the outpatient setting or parental decision making for children who are too young to participate in the process.

We have found literature addressing several elements of the model as they relate to patientclinician communication, such as information disclosure and trust. Other elements of a the model have a small but growing body of research directly addressing surrogate decision making, such as emotional support. A few studies have also examined the impact of surrogate-clinician communication on patient and surrogate outcomes such as time in the ICU or surrogate distress.

More work is needed to test the relationships proposed in this model. For example, there is little empirical evidence about whether elements of good communication such as information disclosure or emotional support lead to high quality decision making, defined as decisions that are informed, concordant with and endorsed by both the surrogate and clinician. The surrogate's level of trust may also affect the quality of decisions. Future work is also needed to determine if interventions targeted at improving communication could reduce surrogate distress or reduce aggressive care at the end of life for those patients who die in the hospital. We hope our model will be useful in the design of observational and interventional research aimed at answering these questions, with the long term goal of improving outcomes for surrogate decision makers and patients. Such findings will also have implications for clinical practice by emphasizing the importance of good communication with the surrogate when the patient is hospitalized.

\section{Acknowledgments}

Dr. Torke was supported by a Geriatrics Health Outcomes Research Scholars Award sponsored by the American Geriatrics Society and the John A. Hartford Foundation, and currently holds a career development award from the National Institute on Aging (K23AG031323).

The authors would like to acknowledge Christopher Callahan, MD, for comments on an earlier draft of this manuscript. 


\section{References}

1. Dubler NN. The doctor-proxy relationship: the neglected connection. Kennedy Inst Ethics J. Dec; 1995 5(4):289-306. [PubMed: 10153758]

2. Post LF, Blustein J, Dubler NN. The doctor-proxy relationship: an untapped resource: introduction. J Law Med Ethics. Spring;1999 27(1):5-12. [PubMed: 11657143]

3. Torke AM, Alexander GC, Lantos J, Siegler M. The physician-surrogate relationship. Arch Intern Med. Jun 11; 2007 167(11):1117-1121. [PubMed: 17563018]

4. Baker R, Wu AW, Teno JM, et al. Family satisfaction with end-of-life care in seriously ill hospitalized adults. J Am Geriatr Soc. May; 2000 48(5 Suppl):S61-69. [PubMed: 10809458]

5. Teno JM, Clarridge BR, Casey V, et al. Family perspectives on end-of-life care at the last place of care. J Amer Med Assoc. Jan 7; 2004 291(1):88-93.

6. Abbott KH, Sago JG, Breen CM, Abernethy AP, Tulsky JA. Families looking back: one year after discussion of withdrawal or withholding of life-sustaining support.[see comment]. Crit Care Med. Jan; 2001 29(1):197-201. [PubMed: 11176185]

7. Breen CM, Abernethy AP, Abbott KH, Tulsky JA. Conflict associated with decisions to limit lifesustaining treatment in intensive care units.[see comment]. Journal of General Internal Medicine. May; 2001 16(5):283-289. [PubMed: 11359545]

8. Torke AM, Siegler M, Abalos A, Moloney RM, Alexander GC. Physicians' experiences with surrogate decision making for hospitalized adults. J Gen Intern Med. 2009; 24:1023-1028. [PubMed: 19633896]

9. Lautrette A, Darmon M, Megarbane B, et al. A communication strategy and brochure for relatives of patients dying in the ICU.[see comment]. New England Journal of Medicine. Feb 1; 2007 356(5): 469-478. [PubMed: 17267907]

10. Buchanan, Brock. Deciding for others: The ethics of surrogate decision making. Cambridge: Cambridge University Press; 1990.

11. Emanuel EJ, Emanuel LL. Proxy decision making for incompetent patients. An ethical and empirical analysis. J Amer Med Assoc. Apr 15; 1992 267(15):2067-2071.

12. Watzlawick, P.; Beavin, JH.; Jackson, DD. Pragmatics of human communication: A stud of interactional patterns, pathologies and paradoxes. New York: W. W. Norton and Company; 1967.

13. Baxter, LA.; Braithwaite, DO. Engaging theories in interpersonal communication: multiple perspectives. Los Angeles: Sage Publications; 2008.

14. O'Connor AM. Validation of a Decisional Conflict Scale. Med Dec Making. 1995; 15:25.

15. O'Connor AM. A decision aid for women considering hormone therapy after menopause: decision support framework and evaluation. Patient Educ Couns. 1995; 33:267-279.

16. Epstein, RM.; Street, RL, Jr. Patient-Centered Communication In Cancer Care: Promoting Healing and Reducing Suffering. Bethesda, MD: National Cancer Center; 2007.

17. Kleinman, A. Patients and healers in the context of culture. Berkeley, CA: University of California Press; 1980.

18. Krantz DS, Baum A, Wideman M. Assessment of Preferences for self-treatment and information in health care. J Pers Soc Psychol. Nov; 1980 39(5):977-990. [PubMed: 7441487]

19. Benbassat J, Pilpel D, Tidhar M. Patients' preferences for participation in clinical decision making: a review of published surveys. Behav Med. Summer;1998 24(2):81-88. [PubMed: 9695899]

20. Torke AM, Corbie-Smith GM, Branch WT Jr. African American patients' perspectives on medical decision making. Arch Intern Med. Mar 8; 2004 164(5):525-530. [PubMed: 15006829]

21. Jenkins V, Fallowfield L, Saul J. Information needs of patients with cancer: results from a large study in UK cancer centres. Br J Cancer. Jan 5; 2001 84(1):48-51. [PubMed: 11139312]

22. Cox A, Jenkins V, Catt S, Langridge C, Fallowfield L. Information needs and experiences: an audit of UK cancer patients. Eur J Oncol Nurs. Sep; 2006 10(4):263-272. [PubMed: 16376146]

23. Petronio, S. Boundaries of privacy: dialectics of disclosure. Albany, NY: State University of New York Press; 2002.

24. Helft PR, Petronio S. Communication pitfalls with cancer patients: "hit-and-run" deliveries of bad news. J Am Coll Surg. Dec; 2007 205(6):807-811. [PubMed: 18035266] 
25. Serewicz MCM, Canary DJ. Assessments of disclosure from the in-laws: Links among disclosure topics, family privacy orientation, and relational quality. Journal of Social and Personal Relationships. 2008; 25:333-357.

26. Levine C. HIPAA and talking with family caregivers: What does the law really say? Am J Nursing. 2006; 106:51-53.

27. Louis MR. Surprise and sense making: What newcomers experience in entering unfamiliar organizational settings. Administrative Science Quarterly. 1980; 25:226-251. [PubMed: 10247029]

28. Weick KE, Sutcliffe KM, Obstfeld D. Organizing and the process of sensemaking. Organization Science. 2005; 16:1526-5455.

29. Buckman, R.; Kason, Y. How to break bad news: A guide for health care professionals. Baltimore, MD: Johns Hopkins University Press; 1992.

30. Frankel RM, Stein T. Getting the most out of the clinical encounter: the four habits model. J Med Pract Manage. Jan-Feb; 2001 16(4):184-191. [PubMed: 11317576]

31. Krupat E, Frankel R, Stein T, Irish J. The Four Habits Coding Scheme: validation of an instrument to assess clinicians' communication behavior. Patient Educ Couns. Jul; 2006 62(1):38-45. [PubMed: 15964736]

32. Torke, AM.; Abalos, A.; Siegler, M.; Alexander, GC. Communicating with Surrogates: A Physician Survey. Poster presentation, Society of General Internal Medicine Annual Meeting; Toronto, Ontario. 2007.

33. Lilly CM, De Meo DL, Sonna LA, et al. An intensive communication intervention for the critically ill. American Journal of Medicine. Oct 15; 2000 109(6):469-475. [PubMed: 11042236]

34. Wachter RM, Pantilat SZ. The "continuity visit" and the hospitalist model of care. Dis Mon. Apr; 2002 48(4):267-272. [PubMed: 12021759]

35. Beach MC, Inui T. Relationship-centered care. A constructive reframing. J Gen Intern Med. Jan; 2006 21( Suppl 1):S3-8. [PubMed: 16405707]

36. Azoulay E, Pochard F, Kentish-Barnes N, et al. Risk of post-traumatic stress symptoms in family members of intensive care unit patients. Am J Respir Crit Care Med. May 1; 2005 171(9):987994. [PubMed: 15665319]

37. Butcher HK, Holkup PA, Park M, Maas M. Thematic analysis of the experience of making a decision to place a family member with Alzheimer's disease in a special care unit. Res Nurs Health. Dec; 2001 24(6):470-480. [PubMed: 11746076]

38. A thematic analysis of Korean family caregivers' experiences in making the decision to place a family member with dementia in a long-term care facility. Research in Nursing \& Health. Oct; 2004 27(5):345-356. [PubMed: 15362145]

39. Jacob DA. Family members' experiences with decision making for incompetent patients in the ICU: a qualitative study. Am J Crit Care. Jan; 1998 7(1):30-36. [PubMed: 9429681]

40. Chambers-Evans J, Carnevale FA. Dawning of awareness: the experience of surrogate decision making at the end of life. Journal of Clinical Ethics. 2005; 16(1):28-45. [PubMed: 15915844]

41. Vig EK, Taylor JS, Starks H, Hopley EK, Fryer-Edwards K. Beyond substituted judgment: How surrogates navigate end-of-life decision-making. J Am Geriatr Soc. Nov; 2006 54(11):1688-1693. [PubMed: 17087695]

42. Vig EK, Starks H, Taylor JS, Hopley EK, Fryer-Edwards K. Surviving surrogate decision-making: what helps and hampers the experience of making medical decisions for others. J Gen Intern Med. Sep; 2007 22(9):1274-1279. [PubMed: 17619223]

43. Braun UK, Beyth RJ, Ford ME, McCullough LB. Voices of African American, Caucasian, and Hispanic surrogates on the burdens of end-of-life decision making. J Gen Intern Med. Mar; 2008 23(3):267-274. [PubMed: 18172738]

44. Swigart V, Lidz C, Butterworth V, Arnold R. Letting go: family willingness to forgo life support. Heart Lung. Nov-Dec; 1996 25(6):483-494. [PubMed: 8950128]

45. Tilden VP, Tolle SW, Nelson CA, Fields J. Family decision-making to withdraw life-sustaining treatments from hospitalized patients. Nurs Res. Mar-Apr; 2001 50(2):105-115. [PubMed: 11302290] 
46. Callahan CM, Haag KM, Buchanan NN, Nisi R. Decision-making for percutaneous endoscopic gastrostomy among older adults in a community setting. J Am Geriatr Soc. Sep; 1999 47(9):11051109. [PubMed: 10484254]

47. Lewis CL, Hanson LC, Golin C, et al. Surrogates' perceptions about feeding tube placement decisions. Patient Educ Couns. May; 2006 61(2):246-252. [PubMed: 16503108]

48. Wendler D, Rid A. Systematic Review: The effects on surrogates of making treatment decisions for others. Ann Intern Med. 2011; 154:336-346. [PubMed: 21357911]

49. Torke AM, Simmerling M, Siegler M, Kaya D, Alexander GC. Rethinking the ethical framework for surrogate decision making: a qualitative study of physicians. J Clin Ethics. Summer;2008 19(2):110-119. [PubMed: 18767471]

50. McDonagh JR, Elliott TB, Engelberg RA, et al. Family satisfaction with family conferences about end-of-life care in the intensive care unit: increased proportion of family speech is associated with increased satisfaction. Crit Care Med. Jul; 2004 32(7):1484-1488. [PubMed: 15241092]

51. Selph RB, Shiang J, Engelberg R, Curtis JR, White DB. Empathy and life support decisions in intensive care units. J Gen Intern Med. Sep; 2008 23(9):1311-1317. [PubMed: 18574641]

52. Pochard F, Azoulay E, Chevret S, et al. Symptoms of anxiety and depression in family members of intensive care unit patients: ethical hypothesis regarding decision-making capacity. Crit Care Med. Oct; 2001 29(10):1893-1897. [PubMed: 11588447]

53. Schofield PE, Butow PN, Thompson JF, Tattersall MH, Beeney LJ, Dunn SM. Psychological responses of patients receiving a diagnosis of cancer. Ann Oncol. Jan; 2003 14(1):48-56. [PubMed: 12488292]

54. Armstrong K, Rose A, Peters N, Long JA, McMurphy S, Shea JA. Distrust of the health care system and self-reported health in the United States. J Gen Intern Med. Apr; 2006 21(4):292-297. [PubMed: 16686803]

55. Balkrishnan R, Dugan E, Camacho FT, Hall MA. Trust and satisfaction with physicians, insurers, and the medical profession. Med Care. Sep; 2003 41(9):1058-1064. [PubMed: 12972845]

56. Thom DH, Ribisl KM, Stewart AL, Luke DA. Further validation and reliability testing of the Trust in Physician Scale. The Stanford Trust Study Physicians. Med Care. May; 1999 37(5):510-517. [PubMed: 10335753]

57. Safran DG, Taira DA, Rogers WH, Kosinski M, Ware JE, Tarlov AR. Linking primary care performance to outcomes of care. J Fam Pract. Sep; 1998 47(3):213-220. [PubMed: 9752374]

58. Rose A, Peters N, Shea JA, Armstrong K. Development and testing of the health care system distrust scale. J Gen Intern Med. Jan; 2004 19(1):57-63. [PubMed: 14748861]

59. Karlawish JH, Quill T, Meier DE. A consensus-based approach to providing palliative care to patients who lack decision-making capacity. ACP-ASIM End-of-Life Care Consensus Panel. American College of Physicians-American Society of Internal Medicine. Ann Intern Med. May 18; 1999 130(10):835-840. [PubMed: 10366374]

60. Prendergast TJ. Resolving conflicts surrounding end-of-life care. New Horiz. Feb; 1997 5(1):6271. [PubMed: 9017680]

61. Corley MC, Elswick RK, Gorman M, Clor T. Development and evaluation of a moral distress scale. J Adv Nurs. Jan; 2001 33(2):250-256. [PubMed: 11168709]

62. Hamric AB, Blackhall LJ. Nurse-physician perspectives on the care of dying patients in intensive care units: collaboration, moral distress, and ethical climate. Crit Care Med. Feb; 2007 35(2):422429. [PubMed: 17205001]

63. Krupat EYC, Putnam S. Patient role orientations, doctor-patient fit, and visit satisfaction. Psychology and Health. 2000; 15:707-719.

64. Ende J, Kazis L, Ash A, Moskowitz MA. Measuring patients' desire for autonomy: decision making and information-seeking preferences among medical patients. J Gen Intern Med. Jan-Feb; 1989 4(1):23-30. [PubMed: 2644407]

65. Levinson W, Kao A, Kuby A, Thisted RA. Not all patients want to participate in decision making. A national study of public preferences. J Gen Intern Med. Jun; 2005 20(6):531-535. [PubMed: 15987329] 
66. Krupat E, Bell RA, Kravitz RL, Thom D, Azari R. When physicians and patients think alike: patient-centered beliefs and their impact on satisfaction and trust. J Fam Pract. Dec; 2001 50(12): 1057-1062. [PubMed: 11742607]

67. Charles C, Gafni A, Whelan T. Shared decision-making in the medical encounter: what does it mean? (or it takes at least two to tango). Soc Sci Med. Mar; 1997 44(5):681-692. [PubMed: 9032835]

68. Makoul G, Clayman ML. An integrative model of shared decision making in medical encounters. Patient Educ Couns. Mar; 2006 60(3):301-312. [PubMed: 16051459]

69. Mandelblatt J, Kreling B, Figeuriedo M, Feng S. What is the impact of shared decision making on treatment and outcomes for older women with breast cancer? Journal of Clinical Oncology. Oct 20; 2006 24(30):4908-4913. [PubMed: 16983102]

70. van Dam HA, van der Horst F, van den Borne B, Ryckman R, Crebolder H. Provider-patient interaction in diabetes care: effects on patient self-care and outcomes. A systematic review. Patient Educ Couns. Sep; 2003 51(1):17-28. [PubMed: 12915276]

71. Kaplan SK, Greenfield S, Ware JE. Assessing the effects of physician-patient interactions on the outcomes of chronic disease. Medical Care. 1989; 27(Suppl 3):S110-S127. [PubMed: 2646486]

72. Teno JM, Casey VA, Welch LC, Edgman-Levitan S. Patient-focused, family-centered end-of-life medical care: views of the guidelines and bereaved family members. Journal of Pain \& Symptom Management. Sep; 2001 22(3):738-751. [PubMed: 11532587]

73. Jonsen, AR.; Siegler, M.; Winslade, W. Clinical Ethics: A Practical Approach to Ethical Decisions in Clinical Medicine. 6. New York: McGraw-Hill; 2006.

74. Shalowitz DI, Garrett-Mayer E, Wendler D. The accuracy of surrogate decision makers: a systematic review. Arch Intern Med. Mar 13; 2006 166(5):493-497. [PubMed: 16534034]

75. Fagerlin A, Schneider CE. Enough: The Failure of the Living Will. Hastings Cent Rep. 2004; 34(2):30-42. [PubMed: 15156835]

76. Fagerlin A, Ditto PH, Danks JH, Houts RM, Smucker WD. Projection in surrogate decisions about life-sustaining medical treatments. Health Psychology. May; 2001 20(3):166-175. [PubMed: 11403214]

77. Torke AM, Alexander GC, Lantos J. Substituted Judgment: The Limitations of Autonomy in Surrogate Decision Making. J Gen Intern Med. Jul 10.2008

78. Brudney D. Choosing for another: beyond autonomy and best interests. Hastings Cent Rep. MarApr; 2009 39(2):31-37. [PubMed: 19388384]

79. Swetz KM, Crowley ME, Hook C, Mueller PS. Report of 255 clinical ethics consultations and review of the literature. Mayo Clin Proc. Jun; 2007 82(6):686-691. [PubMed: 17550748]

80. Siegler M. The physician-patient accommodation: a central event in clinical medicine. Arch Intern Med. Oct; 1982 142(10):1899-1902. [PubMed: 7125771]

81. SUPPORT. A Controlled Trial to Improve Care for Seriously Ill Hospitalized Patients: The Study to Understand Prognoses and Preferences for Outcomes and Risks of Treatments (SUPPORT). J Amer Med Assoc. November 22/29; 1995 274(20):1591-1598.

82. Teno JM, Fisher ES, Hamel MB, Coppola K, Dawson NV. Medical care inconsistent with patients' treatment goals: association with 1-year Medicare resource use and survival. J Am Geriatr Soc. Mar; 2002 50(3):496-500. [PubMed: 11943046]

83. Cosgriff JA, Pisani M, Bradley EH, O’Leary JR, Fried TR. The association between treatment preferences and trajectories of care at the end-of-life. J Gen Intern Med. Nov; 2007 22(11):15661571. [PubMed: 17874168]

84. Lilly CM, Sonna LA, Haley KJ, Massaro AF. Intensive communication: four-year follow-up from a clinical practice study. Crit Care Med. May; 2003 31(5 Suppl):S394-399. [PubMed: 12771590]

85. Schneiderman LJ. Effect of Ethics consultations on non-beneficial life-sustaining treatments in the intensive care setting: A randomized control trial. JAMA. 2003; 290:1166-1172. [PubMed: 12952998]

86. Temel JS, Greer JA, Muzikansky A, et al. Early palliative care for patients with metastatic nonsmall-cell lung cancer. N Engl J Med. Aug 19; 2010 363(8):733-742. [PubMed: 20818875]

87. Esserman L, Belkora J, Lenert L. Potentially ineffective care. A new outcome to assess the limits of critical care. Jama. Nov 15; 1995 274(19):1544-1551. [PubMed: 7474223] 
88. Afessa B, Keegan MT, Mohammad Z, Finkielman JD, Peters SG. Identifying potentially ineffective care in the sickest critically ill patients on the third ICU day. Chest. Dec; 2004 126(6): 1905-1909. [PubMed: 15596691]

89. Engel SE, Kiely DK, Mitchell SL. Satisfaction with end-of-life care for nursing home residents with advanced dementia. J Am Geriatr Soc. Oct; 2006 54(10):1567-1572. [PubMed: 17038076]

90. Christakis NA, Allison PD. Mortality after the hospitalization of a spouse. N Engl J Med. Feb 16; 2006 354(7):719-730. [PubMed: 16481639] 


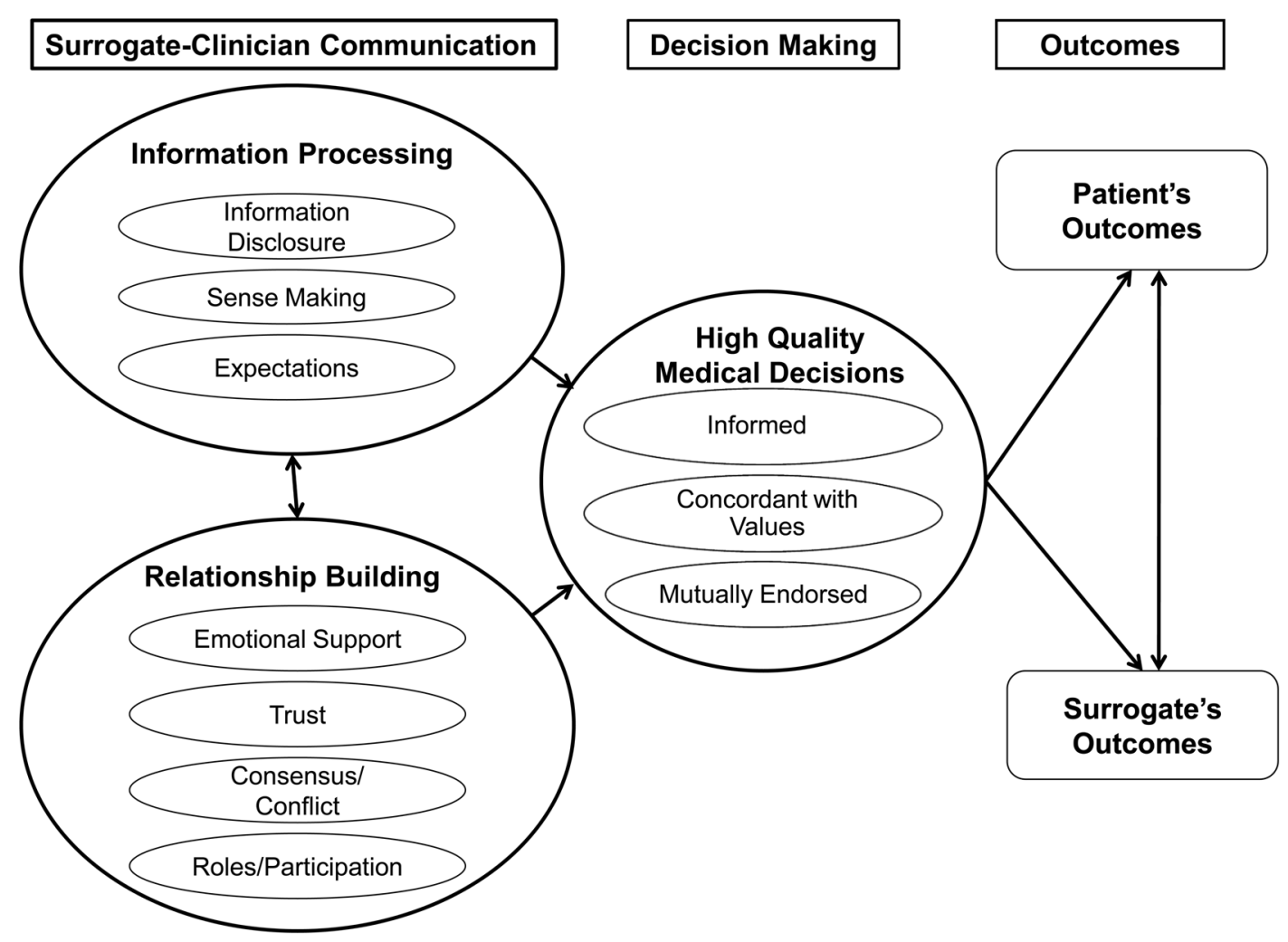

Figure.

Conceptual Model of Communication and Surrogate Decision Making 